\title{
Use of unlicensed and off-label drugs in neonates in a Brazilian university hospital
}

\author{
Adriana Cristina de Souza Gonçalves', Adriano Max Moreira Reis ${ }^{2}$, Ana Carolina Gusmão \\ Marçal' $^{2}$, Maria Cândida Ferrarez Bouzada ${ }^{3}$
}

\begin{abstract}
${ }^{1}$ Pharmacy Service, Hospital das Clínicas, Federal University of Minas Gerais, Belo Horizonte, MG, Brazil, ${ }^{2}$ Faculty of Pharmacy, Federal University of Minas Gerais, Belo Horizonte, MG, Brazil, ${ }^{3}$ Department of Pediatrics, Faculty of Medicine, Hospital das Clínicas, Federal University of Minas Gerais, Belo Horizonte, MG, Brazil
\end{abstract}

\begin{abstract}
This study was designed to investigate the use of off-label and unlicensed drugs in a Neonatal Care Unit (NCU) and to compare the frequency of use of off-label drugs according to the drug regulatory agencies in Brazil (Agência Nacional de Vigilância Sanitária-ANVISA) and the United States Food and Drug Administration (FDA). A prospective observational study was carried out in the NCU. Prescriptions were classified as off-label and unlicensed using both ANVISA and FDA criteria. A total of 157 newborns and 1187 prescriptions were analyzed. The most prescribed drug was fentanyl (9.3\%), followed by multivitamin (8.4\%) and gentamicin (7.9\%). According to ANVISA criteria, there were $665(56.0 \%)$ offlabel prescriptions and $86(7.2 \%)$ unlicensed prescriptions and $95.5 \%$ of newborns received at least one drug off-label. By contrast, according to FDA criteria, there were 592 (49.9\%) off-label prescriptions and $84(7.1 \%)$ unlicensed prescriptions, and $72.0 \%$ of newborns received at least one drug off-label. The offlabel use of drugs registered by ANVISA differed significantly from that of drugs registered by the FDA. There was a high frequency of off-label and unlicensed drug use in the investigated NCU, and there was an inverse relationship between off-label and unlicensed usage and the gestational age of the newborns.
\end{abstract}

Keywords: Drugs/use/University Hospital/Brazil. Drug/use/off-label/unlicensed. Drug therapy. Neonatology. University Hospital/Brazil.

\section{INTRODUCTION}

Pediatric newborns are excluded from clinical trials because of ethical and methodological factors, which include difficulties in conducting clinical trials because of ethical issues, the small number of specialists in pediatric pharmacology, difficulties in the development of pediatric formulations, and low financial returns for the pharmaceutical industry (Dell'Aera et al., 2007; Cuzzolin, Atzei, Fanos, 2006).

The lack of participation of children in clinical research studies is most evident during analyses of the use of drugs in neonates. The scarce number of clinical trials that involve neonates is a consequence of scientific and regulatory challenges, but investigating drugs in neonates is critical (Davis, Connor, Wood, 2012; Dell'Aera et al.,

\footnotetext{
*Correspondence: A. M. M. Reis. Faculdade de Farmácia, Universidade Federal de Minas Gerais. Av Antônio Carlos 6627 Campus Pampulha, Belo Horizonte, MG, Brazil. E-mail: amreis@outlook.com
}

2007; Cuzzolin, Atzei, Fanos, 2006).

There is little evidence on the safety and effectiveness of drugs used in neonates, especially in preterm infants. Over $90 \%$ of commercially available drugs have not been approved by the United States Food and Drug Administration (FDA) for use in neonates. Furthermore, appropriate formulations for use in neonates may not exist (Davis, Connor, Wood, 2012).

This scenario leads to the off-label use of drugs, namely the use of drugs with a dose, age, or route of administration that is different from those described on the drug label (Carvalho et al., 2012; Neubert et al., 2010; Carvalho et al., 2003). It is also a common practice to use unlicensed medicines that encompass one or more of the following situations: modification of the drug dosage form for medicines registered in a sanitary agency, drug compounding, direct use of chemically pure substances as a medicine, and the use of medicines not yet registered in this country, but that are available through importation (Neubert et al., 2010, O’Donnell, Stone, Morley, 2002). 
A systematic review of studies about the use of medications in children revealed that the frequency of unlicensed and off-label drug use in neonatal units was higher than that in pediatric units (Pandolfini, Bonati, 2005). The percentage of neonates who were exposed to at least one off-label or unlicensed drug ranged from $70.0 \%$ to $97.0 \%$ in published studies from several countries (De Souza et al., 2016; Lass et al., 2011; Neubert et al., 2010; O'Donnell, Stone, Morle, 2002).

In Brazil, studies published about the use of offlabel and unlicensed drugs in neonatology showed a high prevalence of this practice (De Souza et al., 2016; Carvalho et al., 2012). The off-label use in one study was analyzed only considering information included in the FDA registration of drugs (Carvalho et al., 2012). Another study was based on the British National Formulary for Children and Drugdex Micromedex ${ }^{\mathrm{TM}}$ (De Souza et al, 2016). The off-label use of drugs for use in neonatology was not evaluated using ANVISA as a source of information in any study that was carried out in Brazil.

In this present study, we investigated the use of offlabel and unlicensed drugs in a neonatal intensive care unit and compared the frequency of off-label and unlicensed drug use according to the drug regulatory agency in Brazil (National Health Surveillance Agency-ANVISA) and FDA in the United States.

\section{METHODS}

\section{Study design and participants}

This prospective study was conducted at the neonatal care unit (NCU) of a university hospital in Brazil between January and June 2012. Newborn monitoring occurred throughout the entire hospitalization period. The NCU was located in a teaching hospital that specializes in the treatment of newborns from high-risk pregnancies. The hospital had a total installed capacity of 467 beds, including 24 that were in the NCU. The NCU was a neonatal unit of intensive care type $\mathrm{B}$, as there were no restrictions on the use of mechanical ventilation or provision of assistance to patients undergoing major surgery (Vermont Oxford Network, 2009).

The study included all newborns admitted to the NCU during the investigation period for more than 24 $\mathrm{h}$ hospitalization, who were prescribed at least one drug during the hospitalization period, and whose parents and/or legal guardians signed an informed consent form. Newborns who remained in the NCU for less than $24 \mathrm{~h}$ and whose parents and/or legal guardian did not agree to participate in the study were excluded. This study was approved by the University Ethics Research Committee (approval number CAAE-0292.0.203.000-11).

\section{Data collection}

Perinatal and demographic information for the neonates was obtained from medical records. Newborns were classified as preterm $(<37$ weeks) or term $(\geq 37$ weeks) according to their gestational age. The preterm group was further subdivided into extremely preterm infants (gestational age $<28$ weeks), very preterm (gestational age of 28-30 weeks), late preterm (gestational age of 31-33 weeks), and preterm (gestational age of 34-36 weeks) (Neubert et al., 2010). The birth weight variable was categorized as either non-low birth weight $(\geq 2500 \mathrm{~g})$ or low birth weight $(\leq 2499 \mathrm{~g})$. The low birth weight group was further subdivided into low birth weight (2499-1500 g), very low birth weight (1499 to $1000 \mathrm{~g}$ ), and extremely low birth weight $(<1000 \mathrm{~g})(\mathrm{Ho}, 1997)$.

Study prescription refers to each drug that was prescribed along with its respective daily dose, number of doses per day, and route of administration; these data were collected from prescription charts. All prescriptions for the period of hospitalization were included in this study. Data collection occurred on all days of the week, including weekends. The following prescription solutions were excluded: $0.9 \%$ sodium chloride, $5 \%$ dextrose, blood products (except albumin), heparin for venous access and permeabilization, vaccines, phytomenadione, $1 \%$ silver nitrate eye drops (prescribed at birth for prophylaxis), parenteral nutrition, oxygen, and electrolytes (calcium gluconate, potassium chloride, magnesium sulfate and sodium bicarbonate) (Carvalho et al., 2012).

Drugs were classified as level one (anatomical group) or three (pharmacological subgroup) according to the Anatomical Therapeutic Chemical (ATC) classification system (WHO, 2014). They were also classified into two classes: (a) Unlicensed; this class included (i) unregistered drugs in Brazil or the U.S. that were chemically pure substances; (ii) drugs registered in Brazil or the U.S., but were modified to suit the pediatric needs of a newborn (such as crushing tablets to prepare a suspension or powder); and (iii) imported drugs (drugs imported from a country where they are licensed) (Neubert et al., 2010; O'Donnell, Stone, Morle, 2002); and (b) Off-label; this class included drugs that were used outside of the recommended indication, dose, route of administration, and/or age described in the product registration for the ANVISA and FDA regulations. Off-label analysis for age took the corrected, postnatal age of the preterm group into account (Lass et al., 2011; Neubert et al., 2010; Carvalho et al., 2003; Conroy, McIntyre, Choonara, 
1999). All prescriptions were analyzed by two pharmacists to classify the drugs. In cases of disagreement, we requested review by a neonatologist.

The classification of drugs according to FDA criteria was conducted to compare our results with those of an international institution.

The off-label or unlicensed classifications, according to Brazilian regulations, were based on information contained on the drug label, which was accessed through consultation of the ANVISA site; this institution is responsible for the regulation of medicines in Brazil (Anvisa, 2014). For medicines whose package insert was not available on the site, package inserts of manufacturers of medicines in use at the investigated hospital during the study period were used. The classification of drugs according to the FDA was performed using Drugdex Micromedex ${ }^{\mathrm{TM}}$ (Drugdex, 2014). Micromedex ${ }^{\mathrm{TM}}$ provides registration data and directions approved by the FDA and this classification was used in research to evaluate the offlabel use of prescription drugs (Smith et al., 2012).

\section{Statistical analysis}

We calculated the sample size using the method for estimating the proportions of infinite populations because it would not be possible to estimate the number of newborns that would be admitted during the study period.
To calculate the sample size, a rate of $90.0 \%$ exposure to drugs was used considering previously published studies about drug use in neonatology units (Jacqz-Aigrain, 2011; Neubert et al., 2010; Conroy, McIntyre, Choonara, 1999). To estimate the extent of exposure to drugs of interest, a cohort of 138 newborns was considered to be sufficient, ensuring a margin of error equal to or less than $5 \%$ to the $5 \%$ level of significance.

A descriptive analysis was performed by determining the frequencies and percentages of categorical variables, and measuring the central tendency (mean and median) and dispersion (standard deviation and interquartile range) for quantitative variables. To compare categorical and quantitative variables, the Mann-Whitney test was used. Chi-square and Fisher exact tests were used to compare categorical variables. We used a significance level of 5\%. All statistical analyses were performed using R software, version 2.15.1.

\section{RESULTS}

\section{Descriptive parameters of newborns}

The final recruited cohort included 157 neonates, including 89 (56.7\%) males and 68 (43.3\%) females. Regarding gestational age, $88(56.0 \%)$ were preterm (Table I). The most frequent admission diagnoses were

TABLE I - Perinatal, demographic, clinical, and pharmacotherapeutic characteristics of the 157 neonates

\begin{tabular}{lcc}
\hline Characteristics & & Values \\
\hline Gestational age in weeks & [median (interquartile range)] & $36(33-38)$ \\
$24-27[\mathrm{n}(\%)]$ & $4(2.5)$ & $14(8.9)$ \\
$28-30$ & {$[\mathrm{n}(\%)]$} & $28(17.8)$ \\
$31-33$ & {$[\mathrm{n}(\%)]$} & $46(29.3)$ \\
$34-36$ & {$[\mathrm{n}(\%)]$} & $65(41.4)$ \\
$>37$ & {$[\mathrm{n}(\%)]$} & $89(56.7)$ \\
Gender & {$[$ male (\%)] } & $2350(1805-2915)$ \\
Birth weight & {$[\mathrm{n}(\%)]$} & $66(42.0)$ \\
$\geq 2500 \mathrm{~g}$ & {$[\mathrm{n}(\%)]$} & $68(43.3)$ \\
$2499-1500 \mathrm{~g}$ & {$[\mathrm{n}(\%)]$} & $17(10.8)$ \\
$1499-1000 \mathrm{~g}$ & {$[\mathrm{n}(\%)]$} & $6(3.8)$ \\
$<1000 \mathrm{~g}$ & & \\
Pharmacotherapy & & 1187 \\
Number of prescriptions & & 127 \\
Number of medicines & & $7.6(7.9)$ \\
Number of drugs by newborn [mean (standard deviation)] & & $665(56.0)$ \\
Prescriptions off-label according ANVISA $\mathrm{n}(\%)$ & & $592(49.9)$ \\
Prescriptions off-label according FDA $(\%)$ & $86(7.2)$ \\
Prescriptions unlicensed according ANVISA n (\%) & &
\end{tabular}


disorders related to gestation length and fetal growth. A total of 53 cases $(33.8 \%)$ presented congenital malformations, 40 (25.5\%) had respiratory conditions, and $33(21.0 \%)$ had cardiovascular diseases during the perinatal period.

\section{Drug prescriptions}

The total number of prescriptions written was 1187 , which encompassed 127 medicines. The mean number of drugs prescribed per newborn was 7.6. According to the ATC level 1 classification, drugs for the nervous system (group N) and systemic anti-infectives (group J) were the most frequently prescribed drugs, followed by agents that act on the alimentary tract and metabolism (group A), which comprised 356 (30.0\%), 292 (24.6\%), and 157 (13.2\%) of prescriptions, respectively. Regarding ATC level 5, the most prescribed drug of all prescription items was fentanyl $(9.3 \%)$, followed by multivitamin $(8.4 \%)$ and gentamicin $(7.9 \%)$.

\section{Off-label prescriptions according to ANVISA}

Off-label prescriptions accounted for 665 (56.0\%) of the total according to the ANVISA criteria (Table I). Among the 157 neonates recruited, 150 (95.5\%) received at least one off-label drug. The frequency of off-label drug use was $100.0 \%$ for extreme premature and very preterm newborns. In the other gestational age groups, the proportion of off-label use ranged from $93.8 \%$ to $96.4 \%$.

As shown in Table II, drugs for the nervous system (group N), systemic anti-infectives (group J), and drugs targeting the alimentary tract and metabolism (group A) were the most frequent off-label prescriptions. Fentanyl and multivitamins were the most common off-label prescriptions in all strata of gestational age. The frequency of off-label use of midazolam, gentamicin, dipyrone, dopamine, and aminophylline was notable.

Among the 665 ANVISA off-label drugs, the most frequent off-label prescription category was the dose $(99.5 \%)$, followed by indication $(39.1 \%)$, route of administration $(37.9 \%)$, and age $(35.3 \%)$. Notably, the same drug can be the subject of more than one off-label category use.

\section{Off-label prescriptions according to the FDA}

According to FDA regulations, 592 (49.9\%) of all prescriptions recorded during the study period were offlabel (Table I). Many newborns $(113,72.0 \%)$ received at least one drug off-label. The frequency of off-label drug use for extremely premature and very preterm babies was $100.0 \%$ and $92.9 \%$, respectively. In the other gestational age groups, the proportion of FDA off-label prescriptions ranged between $63.0 \%$ and $73.8 \%$. As shown in Table III, drugs for the nervous system (group N), systemic antiinfectives (group J), and cardiovascular system-targeting drugs (group C) were the most frequently used off-label from the prescriptions. Fentanyl and midazolam were the most frequently prescribed off-label drugs in all strata of gestational age according to FDA regulations. The frequencies of off-label use of gentamicin, ampicillin, cefazolin, cefadroxil, dobutamine, and dopamine were also notable.

TABLE II - ATC group of drugs used off-label according to ANVISA with a rate of use $\geq 4 \%$ among newborns, stratified by gestational age in weeks

\begin{tabular}{|c|c|c|c|c|c|c|c|c|c|c|c|c|c|c|}
\hline \multicolumn{3}{|c|}{$\begin{array}{c}\text { Gestational age } \\
24-27 \text { weeks }\end{array}$} & \multicolumn{3}{|c|}{$\begin{array}{c}\text { Gestational age } \\
28-30 \text { weeks }\end{array}$} & \multicolumn{3}{|c|}{$\begin{array}{c}\text { Gestational age } \\
31-33 \text { weeks }\end{array}$} & \multicolumn{3}{|c|}{$\begin{array}{l}\text { Gestational age } \\
34-36 \text { weeks }\end{array}$} & \multicolumn{3}{|c|}{$\begin{array}{c}\text { Gestational age } \\
\geq 37 \text { weeks }\end{array}$} \\
\hline $\begin{array}{l}\text { ATC } \\
\text { Group } \\
\end{array}$ & $\mathrm{N}$ & $\%$ & $\begin{array}{l}\text { ATC } \\
\text { Group } \\
\end{array}$ & $\mathrm{N}$ & $\%$ & $\begin{array}{c}\text { ATC } \\
\text { Group } \\
\end{array}$ & $\mathrm{N}$ & $\%$ & $\begin{array}{l}\text { ATC } \\
\text { Group } \\
\end{array}$ & $\mathrm{N}$ & $\%$ & $\begin{array}{c}\text { ATC } \\
\text { Group } \\
\end{array}$ & $\mathrm{N}$ & $\%$ \\
\hline $\mathrm{N}$ & 10 & 30.3 & $\mathrm{~N}$ & 32 & 30.8 & A & 32 & 37.6 & $\mathrm{~N}$ & 55 & 34.0 & $\mathrm{~J}$ & 71 & 38.2 \\
\hline $\mathrm{J}$ & 10 & 30.3 & $\mathrm{~J}$ & 32 & 30.8 & $\mathrm{~N}$ & 27 & 31.7 & A & 43 & 26.5 & $\mathrm{~N}$ & 66 & 35.5 \\
\hline $\mathrm{C}$ & 07 & 21.2 & A & 24 & 23.1 & $\mathrm{~J}$ & 15 & 17.6 & $\mathrm{~J}$ & 40 & 24.7 & A & 20 & 10.7 \\
\hline A & 05 & 15.2 & $\mathrm{R}$ & 7 & 6.7 & $\mathrm{R}$ & 6 & 7.1 & $\mathrm{C}$ & 13 & 8.0 & $\mathrm{C}$ & 19 & 10.2 \\
\hline $\mathrm{D}$ & 01 & 3.0 & $\mathrm{D}$ & 6 & 5.7 & D & 2 & 2.4 & $\mathrm{D}$ & 06 & 3.7 & $\mathrm{D}$ & 7 & 3.8 \\
\hline \multirow[t]{4}{*}{ Total } & 33 & 100.0 & $\mathrm{C}$ & 3 & 2.9 & B & 1 & 1.2 & $\mathrm{M}$ & 05 & 3.1 & $\mathrm{~B}$ & 3 & 1.6 \\
\hline & & & Total & 104 & 100.0 & $\mathrm{C}$ & 1 & 1.2 & Total & 162 & 100.0 & Total & 186 & 100.0 \\
\hline & & & & & & $\mathrm{M}$ & 1 & 1.2 & & & & & & \\
\hline & & & & & & Total & 85 & 100.0 & & & & & & \\
\hline
\end{tabular}


Similar to ANVISA, the most frequent off-label prescription category according to FDA regulations was dose $(99.3 \%)$. Regarding indication, route of administration, and age, the proportions of off-label prescription use was $57.6 \%, 53.7 \%$, and $57.3 \%$, respectively.

\section{Unlicensed medicines according to ANVISA and the FDA}

The number of unlicensed drug prescriptions was $86(7.2 \%)$ by ANVISA and $84(7.1 \%)$ by FDA criteria (Table I). Anhydrous caffeine was the most frequently used unlicensed drug according to ANVISA across all ranges of gestational age. Other frequently used unlicensed medicines are shown in Table IV. A total of $30.6 \%$ and $12.7 \%$ of newborns received at least one unlicensed drug according to the ANVISA and FDA criteria, respectively.

\section{Comparison between off-label ANVISA and FDA}

The proportion of off-label drugs (56.0\%) according to the ANVISA regulations was significantly greater than those according to the FDA regulations (49.9\%; P-value $=0.002$ ). Furthermore, the proportion of newborns who used off-label drugs $(95.5 \%)$ by ANVISA criteria was significantly greater than that under the FDA criteria (72.0\%; P-value $<0.001)$.

A comparison between the use of off-label drugs in the different age groups revealed no significant difference for either off-label ANVISA $(\mathrm{P}$-value $=0.85)$ or off-label FDA $(\mathrm{P}$-value $=0.15)$ uses .
For drug groups at ATC Level 1: drugs targeting the nervous system, anti-infectives for systemic use, and musculoskeletal system drugs showed a similar frequency of off-label uses between the FDA and ANVISA criteria.

\section{DISCUSSION}

This study reveals a high prevalence of off-label and unlicensed drug use, according to criteria of both ANVISA and the FDA. Additionally, an inverse relationship between this usage and gestational age of the newborns admitted to the neonatal unit was identified. The high frequency of off-label drug use, particularly among neonates who were 34 weeks or less by gestational age, is consistent with previously published national and international studies (Lass et al., 2011; Neubert et al., 2010; Dell'Aera et al., 2007; Carvalho et al., 2012; O'Donnell, Stone, Morley, 2002; Avenel et al., 2000; Conroy, McIntyre, Choonara, 1999; Turner et al., 1999). However, it is important to highlight the difficulty in comparing these present results with those of previous studies because of differences in the definitions used for off-label and unlicensed drugs in various studies.

Several definitions have been found in the literature for the term off-label and some may even be considered interchangeable with the definition of unlicensed drug. Some researchers include unlicensed drug within the definition of off-label drug (Kimland et al., 2012; Mason, Pirmohamed, Nunn, 2012; Nguyen, Claris, Kassai, 2011; Dessi et al., 2010). For this study, we chose to recognize differences between the two categories and advocate for the use of the two terms. We believe this provides

TABLE III - ATC group of drugs used off-label according to the FDA with a rate of use $\geq 4 \%$ among newborns, stratified by gestational age in weeks

\begin{tabular}{|c|c|c|c|c|c|c|c|c|c|c|c|c|c|c|}
\hline \multicolumn{3}{|c|}{$\begin{array}{c}\text { Gestational age } \\
24-27 \text { weeks }\end{array}$} & \multicolumn{3}{|c|}{$\begin{array}{c}\text { Gestational age } \\
28-30 \text { weeks }\end{array}$} & \multicolumn{3}{|c|}{$\begin{array}{c}\text { Gestational age } \\
31-33 \text { weeks }\end{array}$} & \multicolumn{3}{|c|}{$\begin{array}{c}\text { Gestational age } \\
34-36 \text { weeks }\end{array}$} & \multicolumn{3}{|c|}{$\begin{array}{c}\text { Gestational age } \\
\geq 37 \text { weeks }\end{array}$} \\
\hline $\begin{array}{l}\text { Group } \\
\text { ATC }\end{array}$ & $\mathrm{N}$ & $\%$ & $\begin{array}{c}\text { Group } \\
\text { ATC }\end{array}$ & $\mathrm{N}$ & $\%$ & $\begin{array}{l}\text { Group } \\
\text { ATC }\end{array}$ & $\mathrm{N}$ & $\%$ & $\begin{array}{l}\text { Group } \\
\text { ATC }\end{array}$ & $\mathrm{N}$ & $\%$ & $\begin{array}{l}\text { Group } \\
\text { ATC }\end{array}$ & $\mathrm{N}$ & $\%$ \\
\hline $\mathrm{N}$ & 12 & 38.7 & $\mathrm{~J}$ & 30 & 36.1 & $\mathrm{~N}$ & 26 & 46.4 & $\mathrm{~N}$ & 57 & 48.7 & $\mathrm{~J}$ & 75 & 48.1 \\
\hline $\mathrm{J}$ & 09 & 29.0 & $\mathrm{~N}$ & 29 & 34.9 & $\mathrm{~J}$ & 15 & 26.7 & $\mathrm{~J}$ & 27 & 23.1 & $\mathrm{~N}$ & 49 & 31.4 \\
\hline C & 09 & 29.0 & $\mathrm{C}$ & 12 & 14.5 & A & 03 & 5.4 & $\mathrm{C}$ & 19 & 16.2 & C & 19 & 12.2 \\
\hline A & 01 & 3.3 & $\mathrm{R}$ & 7 & 8.5 & $\mathrm{R}$ & 05 & 8.9 & D & 06 & 5.1 & $\mathrm{M}$ & 07 & 4.5 \\
\hline \multirow[t]{5}{*}{ Total } & 31 & 100.0 & A & 4 & 4.8 & $\mathrm{M}$ & 02 & 3.6 & $\mathrm{M}$ & 05 & 4.3 & $\mathrm{D}$ & 03 & 1.9 \\
\hline & & & B & 1 & 1.2 & D & 02 & 3.6 & A & 03 & 2.6 & B & 03 & 1.9 \\
\hline & & & Total & & 100.0 & $\mathrm{~S}$ & 02 & 3.6 & Total & 117 & 100.0 & Total & 156 & 100.0 \\
\hline & & & & & & B & 01 & 1.8 & & & & & & \\
\hline & & & & & & Total & 56 & 100.0 & & & & & & \\
\hline
\end{tabular}


TABLE IV - Frequency of newborns administered unlicensed ANVISA medicines by gestational age in weeks

\begin{tabular}{|c|c|c|c|c|c|c|c|}
\hline \multirow{5}{*}{ Medicine } & \multicolumn{7}{|c|}{ Gestational age in weeks } \\
\hline & $24-27$ & $28-30$ & 31-33 & $34-36$ & $\geq \mathbf{3 7}$ & \multirow{2}{*}{\multicolumn{2}{|c|}{$\begin{array}{c}\text { Total number of } \\
\text { newborns }\end{array}$}} \\
\hline & \multicolumn{5}{|c|}{ Number of newborns by gestational age } & & \\
\hline & 4 & 14 & 28 & 46 & 65 & & \\
\hline & $\mathrm{n}$ & $\mathbf{N}$ & $\mathrm{n}$ & $\mathrm{n}$ & $\mathbf{N}$ & Total & $\%$ \\
\hline Acetylsalicylic acid tablet & - & - & - & 1 & - & 1 & 0.6 \\
\hline Alprostadil injectable solution & - & - & - & 2 & 1 & 3 & 1.9 \\
\hline Amiodarone oral solution & - & - & - & - & 1 & 1 & 0.6 \\
\hline Caffeine, anhydrous oral solution & 2 & 6 & 10 & 1 & 2 & 21 & 13.4 \\
\hline Captopril oral solution & - & 1 & - & 2 & - & 3 & 1.9 \\
\hline Captopril tablet & - & - & - & 1 & - & 1 & 0.6 \\
\hline Carvedilol oral solution & - & - & - & 1 & - & 1 & 0.6 \\
\hline Carvedilol tablet & - & - & - & 1 & - & 1 & 0.6 \\
\hline Chloral hydrate syrup & 1 & - & - & - & - & 1 & 0.6 \\
\hline Clonidine tablet & - & - & - & - & 1 & 1 & 0.6 \\
\hline Clopidogrel tablet & - & - & - & 1 & - & 1 & 0.6 \\
\hline Codeine, phosphate tablet & - & - & - & - & 1 & 1 & 0.6 \\
\hline Digoxin tablet & - & - & - & - & 1 & 1 & 0.6 \\
\hline Folic acid tablet & - & - & - & - & 1 & 1 & 0.6 \\
\hline Furosemide oral solution & 1 & 1 & - & - & 2 & 4 & 2.5 \\
\hline Hydrochlorothiazide oral solution & 1 & 1 & - & 3 & - & 5 & 3.2 \\
\hline Hydrochlorothiazide tablet & - & 1 & - & - & - & 1 & 0,6 \\
\hline Indomethacin oral solution & 1 & 1 & 1 & - & - & 3 & 1.9 \\
\hline Lorazepam oral solution & 1 & - & - & 3 & 1 & 5 & 3.2 \\
\hline Methadone oral solution & - & 2 & 1 & 3 & 1 & 7 & 4.5 \\
\hline Methadone oral tablet & - & - & - & 2 & - & 2 & 1.3 \\
\hline Methimazole oral solution & - & 1 & - & - & - & 1 & 0.6 \\
\hline Methylcellulose eye drops & - & - & - & 1 & - & 1 & 0.6 \\
\hline Nifedipine oral solution & - & - & & - & 1 & 1 & 0.6 \\
\hline Phenylephrine ophthalmic solution & - & - & 1 & 1 & 1 & 3 & 0.6 \\
\hline Phenytoin sodium tablet & - & - & - & 1 & - & 1 & 0.6 \\
\hline Propylthiouracil tablet & - & 1 & - & - & - & 1 & 0.6 \\
\hline Pyrimethamine powder for oral use & - & - & - & - & 1 & 1 & 0.6 \\
\hline Pyrimethamine tablet & - & - & - & - & 1 & 1 & 0.6 \\
\hline Sildenafil oral solution & - & - & - & 1 & - & 1 & 0.6 \\
\hline Sildenafil tablet & - & - & - & 1 & - & 1 & 1.3 \\
\hline Spironolactone tablet & - & - & - & 1 & - & 1 & 0.6 \\
\hline Spironolactone oral solution & - & 1 & - & 2 & 1 & 4 & 2.5 \\
\hline Sulfadiazine tablet & - & - & - & - & 1 & 1 & 0.6 \\
\hline Sulfadiazine oral solution & - & - & - & - & 1 & 1 & 0.6 \\
\hline Thyroxine tablet & - & 1 & - & - & - & 1 & 0.6 \\
\hline Ursodeoxycholic acid tablet & - & - & - & 1 & - & 1 & 0.6 \\
\hline
\end{tabular}


a better scaling of the problem, especially for research conducted in hospitals and with an age group with specific pharmacotherapy requirements, such as neonates.

The significant difference detected between the proportion of newborns with off-label prescriptions by the ANVISA and FDA drug regulations reflects the criteria used for medicine licensing and the quality of information provided in drug labels registered by both regulatory agencies. The highest proportion of off-label use by ANVISA standards suggests that the FDA provides more pharmacotherapeutic information and adopts criteria for the registration of medicines and development of labeling that come with the particularities of neonatology. Notably, it will provide more information on specific dosages for the neonatal age group. By contrast, drug labeling authorized by ANVISA frequently includes general dose information for pediatrics without considering the different age groups of neonates. We verify that prescriptions with off-label use, according to FDA criteria, showed a percentage of off-label use for indication, route of administration, and age that was greater than that of off-label according to ANVISA. Therefore, it is necessary that ANVISA undertake a general review of drug labeling to provide clearer and more defined data regarding neonatal use.

The discrepancies of information about drug use in neonatology between ANVISA and FDA identified in this study allow us to speculate whether the high rate of off-label drug use in neonates reflects the lack of studies in this age group or whether it occurs because the results of a few published studies are not reflected in the drug label. It is likely that a combination of the two theories has merit (Allegaert, Tibboel, van den Anker, 2013; Jacqz-Aigrain et al., 2013; Lass et al., 2011; Tafuri et al., 2009).

The percentage of newborns receiving at least one unlicensed drug following ANVISA criteria (30.6 $\%)$ reflects the lack of interest from the Brazilian pharmaceutical industry in the production of medicines for pediatric use. Drugs for which available evidence has shown a positive impact on neonatal care, such as indomethacin and alprostadil, are not marketed in Brazil in drug dosage forms that are suitable for neonates. The economic interests are evident with the recent withdrawal from the Brazilian market of oral liquid formulations for phenytoin and furosemide, motivated by the low number of units sold. The use of unlicensed medicines is an indicator of the need for oral formulations appropriate to the neonates and newborns in the pharmaceutical market in Brazil. Moreover, the association between medication errors and use of unlicensed medicines has been previously described in the literature (Lass et al., 2011; Conroy, 2011).
Given this scenario, the implementation in Brazil of equivalent measures to those of international initiatives developed by the FDA (i.e., the Best Pharmaceuticals for Children Act), the World Health Organization (the Make Medicines Child Size and WHO Model List of Essential Medicines for Children) and the European Medicines Agency (European Union's Pediatric Regulation) has become necessary to increase the availability of safe, effective, and quality medicines for children (Davis, Connor, Wood, 2012; Hopu et al., 2012). These actions must be placed in context with the National Policy for Children's Health and with actions that encompass the drug regulatory agencies, pharmaceutical industry, academia, and those institutions responsible for the selection of drugs for the Brazilian health system. In the selection process of drugs for the health system, the agespecific needs of the neonatal and other pediatric groups should be considered.

To improve our understanding of the off-label and unlicensed use of drugs, we performed an analysis of the pharmacotherapeutic characteristics of drugs included in these categories. Among drugs that act on the nervous system, the highlight was the off-label use of anesthetics and analgesics (ATC level 3). Smith et al. (2012) found that the off-label use of medications is a common occurrence in the United States in the care of children undergoing anesthesia and sedation (Smith et al., 2012). The authors acknowledged the challenges of clinical research with drugs in children and associated ethical and legal issues, but stressed that in this clinical setting, off-label use is a more acceptable practice than deprivation of treatment for a neonate. They mention that off-label use should be based on clinical care guidelines available in the literature and stress the importance of the physician's knowledge of the drugs that they prescribe.

In our study, off-label use occurred in almost all therapeutic classes that we identified. In the group of drugs that act on the alimentary tract and metabolism (ATC group A), the frequency of off-label prescription reflected the protocol of the unit at study, which advocates for the use of multivitamins in oral solution during hospitalization. This medicine was dosed off-label for all prescriptions. In a study carried out in France, as in our present study, multivitamins and an iron salt were the ATC class A drugs that contributed most to the frequency of off-label drug use (Nguyen, Claris, Kassai, 2011).

A systematic review explored the off-label use of sildenafil in the treatment of pulmonary hypertension of newborns. This usage is controversial because of the lack of well-designed clinical studies that demonstrate its safety and effectiveness in neonates (Shah et al., 2011). In 2014, 
the FDA issued a warning about the risks of chronic use of this drug in pediatric newborns, but without showing guidelines regarding use in the neonatal age group (FDA, 2012). Despite this drug having been used in only one newborn during this present study, it reflects the need for its use in neonatal care.

Drugs that act on the cardiovascular system (ATC group C) showed a higher prevalence of off-label use by the FDA criteria than by the ANVISA criteria as a consequence of the lack of indication of dopamine and dobutamine in neonates. However, in clinical practice, these drugs are widely present in clinical guidelines for the management of shock in the newborn. Given this situation and lack of therapeutic alternatives, it is important to seek our adequate information to ensure rational prescribing in neonates (Carvalho et al., 2012).

Hydrochlorothiazide, classified in this study as unlicensed by both the ANVISA and FDA criteria, is used in the treatment of bronchopulmonary dysplasia of the newborn, but lack of knowledge about its longterm effects and efficacy in the clinic explains the lack of inclusion of this statement in the drug registration and the unavailability of drug dosage forms suitable for newborns. This drug, because of the lack of well-designed and controlled studies in neonates, is on the list of therapeutic priorities of the National Institute of Child Health and Human Development (NICHD) for investigation (NIH, 2014). Furosemide and spironolactone, used off-label in this study, also require further investigation to establish their efficacy and safety in bronchopulmonary dysplasia (Segar, 2012).

The prescription of unlicensed or off-label drugs is not illegal and can be clinically justified when there is no alternative therapy. However, it is undoubtedly a procedure associated with risks because of the absence of randomized controlled studies that explore the risk/benefit ratios for a drug (Cuzzolin, Zaccaron, Fanos, 2013). The use of drugs in the neonatal population with insufficient data on pharmacokinetics, pharmacodynamics, and side effects can result in undesirable effects in the short- and/ or long-term. Short-term effects can include sub-dosing, resulting in therapeutic failure, or over-dosing, which implies a high risk of toxicity. Studies have suggested an increased risk of adverse drug reactions because of offlabel use and the need to monitor adverse events associated with such usage (Ballard et al., 2013; Jonville-Bera, Bera, Autret-Leca, 2005).

The safe and appropriate medication use in the neonatal period is an important and complex challenge because of the lack of clear data that should guide decision-making. According to Jain et al. (2012), despite this significant lack of information, physicians are required to optimize drug therapy in neonates and follow-up those results. Many institutions are developing such protocols using advanced tools for quality improvement; however, this practice remains rare.

More important than classifying a drug as offlabel is to determine whether its use is evidence-based. It is important to have evidence that a drug is safe and appropriate to the newborn's clinical condition. Ideally, the evidence should be high level, obtained through well-designed, randomized clinical trials, and include information about the minimum effective dose. Unfortunately, the conditions of pediatric clinical practice are quite different, with a lack of detailed information that ensures safe and effective pharmacotherapy (Bonati, Pandolfini, 2011). Indeed, this study demonstrated that in Brazil the use of medicines for neonates is a serious problem for professionals in the pediatric field.

Updating the labeling of medicines of pediatric interest through evidence-based information represents an important strategy to reduce rates of off-label use and improve rational prescribing (Bonati, Pandolfini, 2011).

The results of this present study should be evaluated in the context of its limitations. In particular, the generalizability of our results is restricted because the study was completed in a NCU of a single tertiary care hospital. Thus, our results may not be applicable to those of less complex institutions. Another limitation is the sample size. It is important to emphasize that the prospective design of the study (covering prescription drugs administered during hospitalization), the classification of off-label (employing criteria of two regulatory agencies), and use of criteria of off-label and unlicensed (based on current literature concepts) are strengths of this study.

The frequency of off-label use of drugs in the neonatal unit investigated in this study was high. Nearly all newborns were exposed to at least one off-label prescription according to ANVISA regulations and $72.0 \%$ according to FDA regulations. In cases of extreme preterm neonates, exposure occurred in $100.0 \%$ of newborns according to both ANVISA and FDA criteria.

Data available about medicines registered in the FDA compared with the data available on medicines authorized by ANVISA is more complete with respect to indications, route of administration, and use according to gestational age.

\section{ACKNOWLEDGEMENTS}

The authors would like to acknowledge Pró-Reitoria de Pesquisa da Universidade Federal de Minas Gerais. 


\section{REFERENCES}

Allegaert K, Tibboel D, Van den Anker J. Pharmacological treatment of neonatal pain: in search of a new equipoise. Semin Fetal Neonatal Med. 2013;18(1):42-7.

Agência Nacional de Vigilância Sanitária. ANVISA. [cited 2014, August]. Available from: www.anvisa.gov.br.

Avenel S, Bomkratz A, Dassieu G, Janaud JC, Danan C. The incidence of prescriptions without marketing product license in a neonatal intensive care unit. Arch Pediatr. 2000;7(2):143-7.

Ballard CD, Peterson GM, Thompson AJ, Beggs SA. Offlabel use of medicines in paediatric inpatients at an Australian teaching hospital. J Paediatr Child Health 2013;49(1):38-42.

Bonati M, Pandolfini C. Off-label drug use in children should be rational. Arch Dis Child. 2011;96(9):870-1.

Carvalho CG, Ribeiro MR, Bonilha MM, Fernandes Jr M, Procianoy RS, Silveira RC. Use of off-label and unlicensed drugs in the neonatal intensive care unit and its association with severity scores. J Pediatr. 2012;88(6):465-70.

Carvalho PR, Carvalho CG, Alievi PT, Martinbiancho J, Trotta EA. Identificação de medicamentos "não apropriados para crianças" em prescrições de unidade de tratamento intensivo pediátrica. J Pediatr. 2003;79(5):397-402.

Conroy S, McIntyre J, Choonara I. Unlicensed and off label drug use in neonates. Arch Dis Child Fetal Neonatal. 1999;80(2):F142-5.

Conroy S. Association between licence status and medication errors. Arch Dis Child. 2011;96(3):305-6.

Cuzzolin L, Atzei A, Fanos V. Off-label and unlicensed prescribing for newborns and children in different settings: a review of the literature and a consideration about drug safety. Expert Opin Drug Saf. 2006;5(5):703-18.

Cuzzolin L, Zaccaron A, Fanos V. Unlicensed and off-label uses of drugs in paediatrics: a review of the literature. Fundam Clin Pharmacol. 2003;17(1):125-31.

Davis JM, Connor EM, Wood AJ. The need for rigorous evidence on medication use in preterm infants: is it time for a neonatal rule? JAMA. 2012; 308(14):1435-6.
De Souza ASJ, Dos Santos DB, Rey LC, Medeiros MG, Vieira $\mathrm{M}$, Coelho HL. Off-label use and harmful potential of drugs in a NCU in Brazil: a descriptive study. BMC Pediatr. 2016;16(1):13.

Dell'Aera M, Gasbarro AR, Padovano M, Laforgia N, Capodiferro D, Solarino B, et al. Unlicensed and off-label use of medicines at a neonatology clinic in Italy. Pharm World Sci. 2007;29(4):361-7.

Dessì A, Salemi C, Fanos V, Cuzzolin L. Drug treatments in a neonatal setting: focus on the off- label use in the first month of life. Pharm World Sci. 2010;32(2):120-4.

Drugdex. Thomson Reuters. Thomson Micromedex database. New York: Thomson Reuters. [cited 2014, August]. Available at: http://www.thomsonhc.com/hcs/libraria.

Food and Drug Administration. FDA. Drug safety communication: FDA clarifies warning about pediatric use of revatio (sildenafil) for pulmonary arterial hypertension. Silver Spring, MD: FDA; 2012. [cited 2015 January]. Available from: http://www.fda.gov/Drugs/DrugSafety/ucm390876.htm.

Ho W. Recommended definition, terminology and format for statistical tables related to the perinatal period. Acta Obstet Gynecol Scand.1997;56:247-53.

Hoppu K, Anabwani G, Garcia-Bournissen F, Gazarian M, Kearns GL, Nakamura H, et al. The status of paediatric medicines initiatives around the world-what has happened and what has not? Eur J Clin Pharmacol. 2012;68(1):1-10.

Jacqz-Aigrain E, Zhao W, Sharland M, van den Anker JN. Use of antibacterial agents in the neonate: 50 years of experience with vancomycin administration. Semin Fetal Neonatal Med. 2013;18(1):28-34.

Jacqz-Aigrain E. Drug policy in Europe: research and funding in neonates: current challenges, future perspectives, new opportunities. Early Hum Dev. 2011;87 (Supl 1):S27-30.

Jain L. The conundrum of off-label and unlicensed drug usage in neonatology. J Pediatr.

2012;88(6):449-51.

Jonville-Bera AP, Bera F, Autret-Leca E. Are incorrectly used drugs more frequently involved in adverse drug reactions? A prospective study. Eur J Clin Pharmacol. 2005;61(3):231-6. 
Kimland E, Nydert P, Odlind V, Böttiger Y, Lindemalm S. Paediatric drug use with focus on off-label prescriptions at Swedish hospitals-a nationwide study. Acta Paediatr. 2012;101(7):772-8.

Lass J, Käär R, Jõgi K, Varendi H, Metsvaht T, Lutsar I. Drug utilisation pattern and off-label use of medicines in Estonian neonatal units. Eur J Clin Pharmacol. 2011;67(12):1263-71.

Mason J, Pirmohamed M, Nunn T. Off-label and unlicensed medicine use and adverse drug reactions in children: a narrative review of the literature. Eur J Clin Pharmacol. 2012;68(1):21-8.

National Institutes of Health. NIH. Best Pharmaceuticals for Children Act (BPCA) priority list of needs in pediatric therapeutics. Bethesda, MD: NIH; 2014. [cited 2015, January]. Available from: https://bpca.nichd.nih.gov/prioritization/status/ Documents/Priority_List_073115.pdf

Neubert A, Lukas K, Leis T, Dormann H, Brune K, Rascher W.Drug utilisation on a preterm and neonatal intensive care unit in Germany: a prospective, cohort-based analysis. Eur J Clin Pharmacol. 2010;66(1):87-95.

Vermont Oxford Network Database manual of operations for infants born in 2009 [manual online], 2009. [cited 2014 November]. Available at: https://portal.vtoxford.org/tools/200 9ManualofOperationswithindex13_2.pdf.

Nguyen KA, Claris O, Kassai B. Unlicensed and off-label drug use in a neonatal unit in France. Acta Paediatr. 2011;100(4):6157.

O’Donnell CP, Stone RJ, Morley CJ. Unlicensed and off-label drug use in an Australian neonatal intensive care unit. Pediatrics. 2002;110(5):e52.
Pandolfini C, Bonati M. A literature review on off-label drug use in children. Eur J Pediatr. 2005;164(9):552-8.

Segar JL. Neonatal diuretic therapy: furosemide, thiazides, and spironolactone. Clin Perinatol. 2012;39(1):209-20.

Shah PS, Ohlsson A. Sildenafil for pulmonary hypertension in neonates. Cochrane Database Syst Rev. 2011;8:CD005494.

Smith MC, Williamson J, Yaster M, Boyd GJ, Heitmiller ES. Off-label use of medications in children undergoing sedation and anesthesia. Anesth Analg. 2012;115(5):1148-54.

Tafuri G, Trotta F, Leufkens HG, Martini N, Sagliocca L, Traversa G. Off-label use of medicines in children: can available evidence avoid useless paediatric trials. Eur J Clin Pharmacol. 2009;65(2):209-16.

Turner SE, Nunn AJ, Fielding K, Choonara IM. Adverse drug reactions to unlicensed and off-label drugs on paediatric wards: a prospective study. Acta Paediatr. 1999;88(9):965-8.

World Health Organization. WHO. Collaboration Centre for Drug Statistics Methodology. Anatomical-TherapeuticalChemical (ATC) Classification - Index and Guidelines. Oslo: Centre for Drug Statistics Methodology; 2014. [cited 2014 August]. Available from: https://www.whocc.no/atc_ddd index/.

Received for publication on $10^{\text {th }}$ January 2017 Accepted for publication on $23^{\text {rd }}$ May 2017 